\title{
Identification of damage mechanisms in concrete under high level creep by the acoustic emission technique
}

\author{
J. Saliba • A. Loukili · F. Grondin · J. P. Regoin
}

\begin{abstract}
Many researchers have proposed hypotheses concerning the physical mechanisms that govern creep and among them the development of microcracks is well recognized. For high load levels, microcracking may initiates at the moment of load application and begins to grow to form a timedependent crack path. An experimental investigation is proposed here in order to provide interesting insight into the coupling between creep and damage with specimens loaded in flexure. The acoustic emission (AE) technique is used as a tool to provide information on the pertinence of the physical hypothesis that microcracks appear during creep. An original test is performed to accelerate the creep phenomenon by submitting concrete beams to desiccation after a basic creep period. The results show a good proportionality between the creep deformation and the AE activity and thus the efficiency of acoustic measurements for the estimation of the state of damage. In addition, an unsupervised pattern recognition analysis is used as a tool for the classification of the monitored $\mathrm{AE}$ signatures. The cluster analysis shows two clusters during basic creep and three clusters during desiccation creep indicating different damage mechanisms.
\end{abstract}

J. Saliba · A. Loukili · F. Grondin $(\varangle) \cdot$ J. P. Regoin Ecole Centrale de Nantes, Institut de Recherche en Génie Civil et Mécanique (GeM), UMR-CNRS 6183,

1 Rue de La Noë, 44321 Nantes, France

e-mail: frederic.grondin@ec-nantes.fr
Keywords Concrete $\cdot$ Creep - Damage $\cdot$ Acoustic emission technique $\cdot$ Flexural test $\cdot$ Multivariable data clustering

\section{Introduction}

Concrete structures are susceptible to degradation due to delayed strains which has an impact on their safety margin and life time, especially when they are subjected to high loading level. Numerous contradictory theories have been put forward over the years to assess the creep behaviour of concrete. Since no single mechanism can account for all the observed phenomena, several major real mechanisms can be distinguished and it is commonly accepted that a combination of these mechanisms acts together. Usually, creep mechanisms are associated with the hydrated cement paste and can be considered as material properties. Microcracking is an apparent creep mechanism that can also contribute to the observed deformation and is responsible of the permanent deformation. Under high loading level, microcracks, initiated by the local stress, develop and interact with the viscoelasticity [1]. Then a deviation of the linearity of the mechanical response may occur and is manifested by tertiary creep $[2,3]$.

The study of creep in tension has shown different effect on the behaviour of concrete with sometimes some contradiction. On one hand, creep may relax 
internal tensile stresses generated by restrained shrinkage by increasing the deformation capacity to the rupture and consequently reducing the risk of potential cracking in concrete $[4,5]$. On the other hand, the principal mechanism of tensile creep is due to the microcracks development which could be responsible of the decrease of the residual strength and the modification of concrete properties $[6,7]$. Many researchers tried to quantify the effect of tensile creep on the behaviour of concrete mainly by measuring the residual strength [8-13]. A recent study conducted by the authors shows, with the acoustic emission (AE) technique, a more brittle behaviour and a decrease in the fracture process zone (FPZ) in specimens subjected to flexural creep [7]. But what is the reason of this brittleness after creep? And how do micro-cracks develop in the microstructure during creep?

The objective of this paper is to suggest an assessment of the damage mechanisms occurring during the different phases of creep. To achieve this, an experimental investigation is proposed on beams loaded with flexural creep at high stress levels. Damage evolution under creep is assessed by using the $\mathrm{AE}$ technique. This non-destructive technique proves to be very effective, especially to check and measure micro-cracking that takes place inside a structure under mechanical loading and it is particularly recommended to detecting and localizing cracks in concrete [14-18]. In our study, basic and desiccation creep were monitored at 70 and $85 \%$ of the maximal strength. The results aim to investigate the ranges of variation of the time response due to creep damage coupled effects.

First of all, the materials and the experimental methods are presented. Then, the flexural creep tests are analyzed. Finally, the characterization of the damage evolution during basic and desiccation creep is suggested by using the AE method.

\section{Experimental program}

\subsection{Material properties}

Concrete specimens were mixed with Portland cement CPA-CEMII 42.5, crushed limestone aggregate distributed in fine sand with a maximum size of $5 \mathrm{~mm}$ and crushed gravel of size 5-12.5 mm. A superplasticizer
Table 1 Concrete mixture proportions

\begin{tabular}{lll}
\hline Constituent & Dosage $\left(\mathrm{kg} / \mathrm{m}^{3}\right)$ & Density $\left(\mathrm{kg} / \mathrm{m}^{3}\right)$ \\
\hline Gravel: G5/12.5 mm & 936.0 & 2,620 \\
Sand: 0/5 mm & 780.0 & 2,570 \\
Cement: CEMII 42.5 & 350.0 & 3,080 \\
Water & 219.5 & 1,000 \\
Superplasticizer & 1.9 & - \\
\hline
\end{tabular}

agent, based on modified polycarboxylic ether polymers, has been added for the workability. Table 1 shows the mix quantities of constituent materials. This mixture is characterized by a water-to-cement (W/C) ratio of 0.56 and a slump of $70 \mathrm{~mm}$. The proportioning of the cement paste, sand and coarse aggregates were kept constant throughout the program.

For the flexural test, $800 \times 200 \times 100 \mathrm{~mm}^{3}$ $(\mathrm{L} \times \mathrm{h} \times \mathrm{b})$ concrete beams were prepared with an effective span (S) equal to $600 \mathrm{~mm}$. The fresh concrete was poured into beam moulds. A plate vibrator was used to compact the concrete in two layers. Then specimens were covered with a thin sheet of plastic to prevent water loss and were maintained in a climatic chamber at a temperature of $20{ }^{\circ} \mathrm{C}$ and a relative humidity (RH) of $95 \% .24 \mathrm{~h}$ after casting, specimens were stripped off from the moulds and kept for curing in lime water, under a temperature condition of $20^{\circ} \mathrm{C}$. Before creep tests, specimens were taken out from the curing tanks and a central notch was formed using a diamond saw cut, with a notch-to-depth ratio of 0.2 $\left(a_{0}=h / 5\right)$

\subsection{Procedure for the three-point bending test}

Three point bending fracture tests were realized to determine the maximum load $\left(F_{\max }\right)$ so we could load the specimens in creep. The fracture test uses a loadcontrolled universal testing machine as per RILEMTMC 50 recommendations [19]. The load was applied with a slow rate of $0.3 \mu \mathrm{m} / \mathrm{s}$, such that the peak load was reached at about $2 \mathrm{~min}$. The averaged maximal strength measured on three specimens is $9.9 \mathrm{kN}$ at 1 month and $10.8 \mathrm{kN}$ at 8 months.

Flexural creep tests were then performed on frames with a capacity ranging from 5 to $50 \mathrm{kN}$. The frames were placed in a climate controlled chamber at $50 \%$ $\mathrm{RH}$ and temperature of $20{ }^{\circ} \mathrm{C}$. The load is applied by gravity with a weight and counterweight system, 


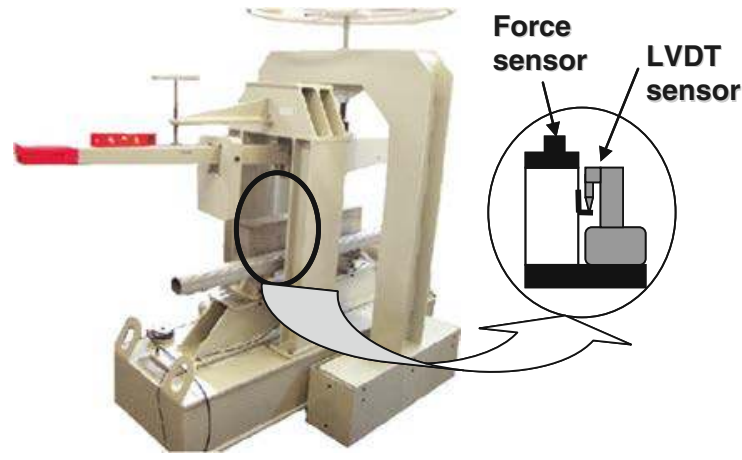

Fig. 1 General view of creep frames

which enables a fine tuning of the load. The displacement was measured at midspan on notched specimens (Fig. 1). For the basic flexural creep tests, the exchange of moisture was prevented by a double layer of self-adhesive aluminium paper. Hence basic creep displacement was considered only.

Two different tests were realized. First of all, basicdesiccation creep tests concerning beams subjected to basic creep and followed by desiccation creep at 70 and $85 \%$ of $F_{\max }$ are realized on specimens at the ages of 1 and 8 months. Those tests allow having a clear idea on the difference between basic and desiccation creep by eliminating the differences between beams due to concrete heterogeneity. Specimens were continuously monitored with the $\mathrm{AE}$ technique during basic and desiccation creep tests till the rupture. Second of all, desiccation creep tests concerning beams subjected to desiccation at 85 and $70 \%$ of $F_{\max }$ were realized and full $\mathrm{AE}$ waveforms were recorded up to failure.

\subsection{Acoustic emission (AE) technique}

The AE system comprised of an eight channel AE Win system, a general-purpose interface bus (PCI-DISP4) and a PC for data storage analysis. Eight piezoelectric transducers (resonant frequency of $150 \mathrm{kHz}$ ) were used to convert the mechanical waves to electrical signals. Transducers were placed around the expected location of the FPZ to minimize errors in the AE event localization program [20]. They were placed in a 3D parallelepiped position on both sides of the specimen, with silicon grease as the coupling aging (Fig. 2). The recorded $\mathrm{AE}$ amplitudes range from 0 to $100 \mathrm{~dB}$. The detected signals were amplified with a $40 \mathrm{~dB}$ gain differential amplifier. In order to overcome the background noise, the signal detection threshold was
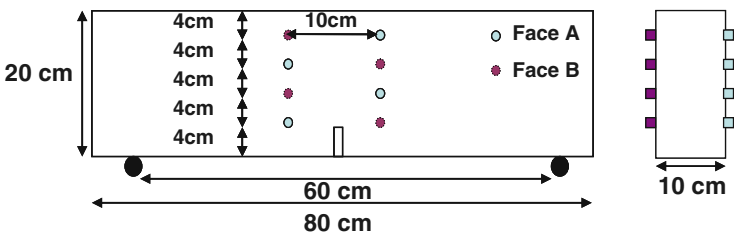

Fig. 2 Specimen geometry and AE transducers position

set at a value of about $35 \mathrm{~dB}$ (value adjusted before every test) slightly above the measured background noise [20]. The acquisition system was calibrated before each test using a pencil lead break procedure HSU-NIELSEN (Norme NF EN 1330). The effective velocity and the attenuation of acoustic waves were also calculated. For this analysis, the effective velocity was assumed to be a constant for the analysis of $\mathrm{AE}$ source locations even though there may be some variability depending on the wave propagation path. The effective velocity was assumed to be $3,800 \mathrm{~m} / \mathrm{s}$. In order to eliminate mechanical and electro-magnetic disturbances, a low-pass filter with a cut-off frequency of $20 \mathrm{kHz}$, and a high-pass filter with a cut-off frequency of $400 \mathrm{kHz}$ were used. Signal descriptors such as rise time, counts, energy, duration, amplitude, average frequency and counts to peak were captured and calculated by AEwin system. Each waveform was digitized and stored. The descriptors were further analyzed and evaluated with the software Noesis.

During the formation of a microcrack, energy is emitted as an elastic wave and propagates from the crack location to the $\mathrm{AE}$ transducers at the specimen surface. The locations of the AE sources are evaluated based on the arrival times of the first wave at each transducer and their respective velocity in concrete specimen. Once the arrival time is picked, the leastsquare method is used to assess the event location. The accuracy of the source location was estimated by applying the pencil lead fracture at a known location on the specimens. The location resolution was estimated to be $\pm 5 \mathrm{~mm}$.

\section{Analysis of the creep displacement}

\subsection{Basic-desiccation creep tests}

Creep displacements measured during the combined basic-desiccation creep tests are shown in Fig. 3. During the basic creep period, creep develops fast in 


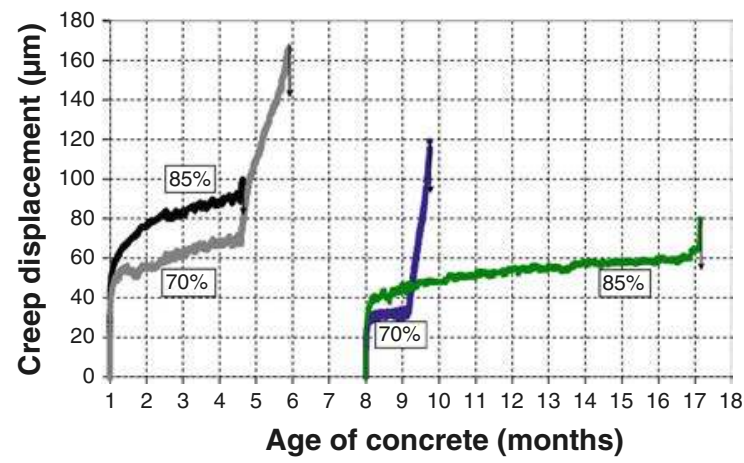

Fig. 3 Combined basic-desiccation creep displacement at 70 and $85 \%$ of the maximal strength

the first days of loading (primary creep) and then stabilizes (secondary creep). The larger the applied stress, the more important are the kinetics and the magnitude of creep displacement. In addition, the ageing results in a decrease of the time-dependent displacement. When subjected to desiccation, creep displacement increases quickly and the beams loaded at $85 \%$ failed few hours later while the beams loaded at $70 \%$ failed after few days. The kinetic of the displacement during desiccation can be divided in two phases. During the first phase, the kinetic is very important and corresponds to the departure of water at the surface and the important desiccation due to water redistribution. The second part presents a lower kinetic in correlation with a more stable shrinkage deformation due to the departure of water inside the beam. Under loading, the bottom part of the beam is under tension and the top part is under compression. So, the microcracked layer due to desiccation in the bottom part of the beam is more extended and tends to loose its residual strength while the upper part of the specimen is forced to contract. This compressed part of the beam has a shrinkage rate more important than the part in tension. The increment of hardening becomes distributed asymmetrically and the neutral axis move upward causing an additional curvature [21, 22].

\subsection{Desiccation creep tests}

Creep displacements obtained with the desiccation creep tests are plotted in Fig. 4. Specimens, loaded at the age of 8 months, failed after 1 day at $85 \%$ and 3 days at $70 \%$. In fact, microcracking initiated due to the applied constant load begins to growth and to form a crack path [6, 23-25].

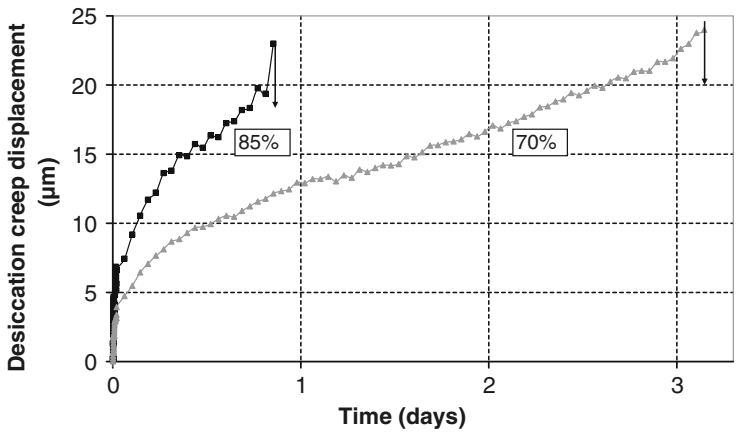

Fig. 4 Desiccation creep displacement at 70 and $85 \%$ of the maximal strength

These tests showed that coupling between creep and damage seems to be more sensible to desiccation. In the following, the AE method has been used in order to understand the phenomena occurred in specimens.

\section{Exploitation of the AE method to identify the creep-damage coupling in a basic-desiccation creep test}

The analysis of the AE data permits real time detection and monitoring of active defects and can reflect the damage mechanisms of the specimen during creep. The combined basic-desiccation creep test realised on the beam aged of 8 months and loaded at $70 \%$ of $F_{\text {max }}$ is analysed in the following. The analysis is made in two steps: the localization of $\mathrm{AE}$ events and then the classification of $\mathrm{AE}$ data.

\subsection{Localization of AE events in concrete during creep}

Figure 5 shows the localization map of the AE sources during basic and desiccation creep. The cumulated locations of acoustic events detected throughout the test are observed over a window in function of the position $\mathrm{x}$ and $\mathrm{y}$, centered at the notch with a width of $200 \mathrm{~mm}$ and covering the beam depth, and in function of the position $y$ and $z$. Each plotted point indicates a detected AE source. The color values indicate the absolute energy of the events, where the absolute energy is defined as the integral of the squared voltage signal divided by the reference resistance $(10 \mathrm{~K} \Omega$ ) over the duration of an acoustic signal. This feature is the true energy measurement of the AE signal and is expressed in atto-joules. 
Fig. 5 Damage localization during a basic creep, b desiccation creep and $\mathbf{c}$ at the rupture in the plane $\mathrm{A}$ and $\mathrm{B}$ (a)

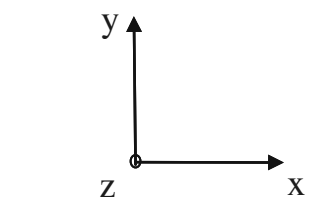

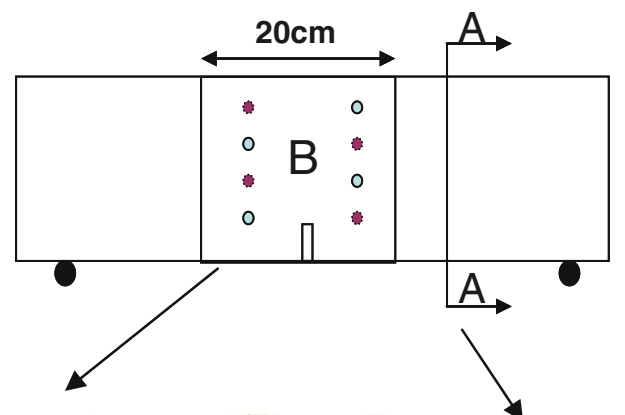
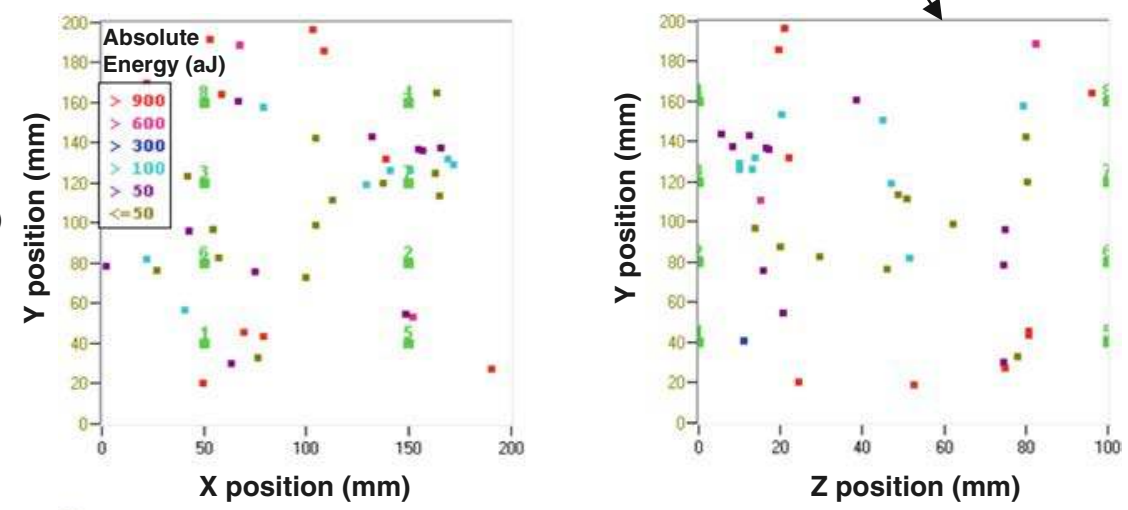

(b)
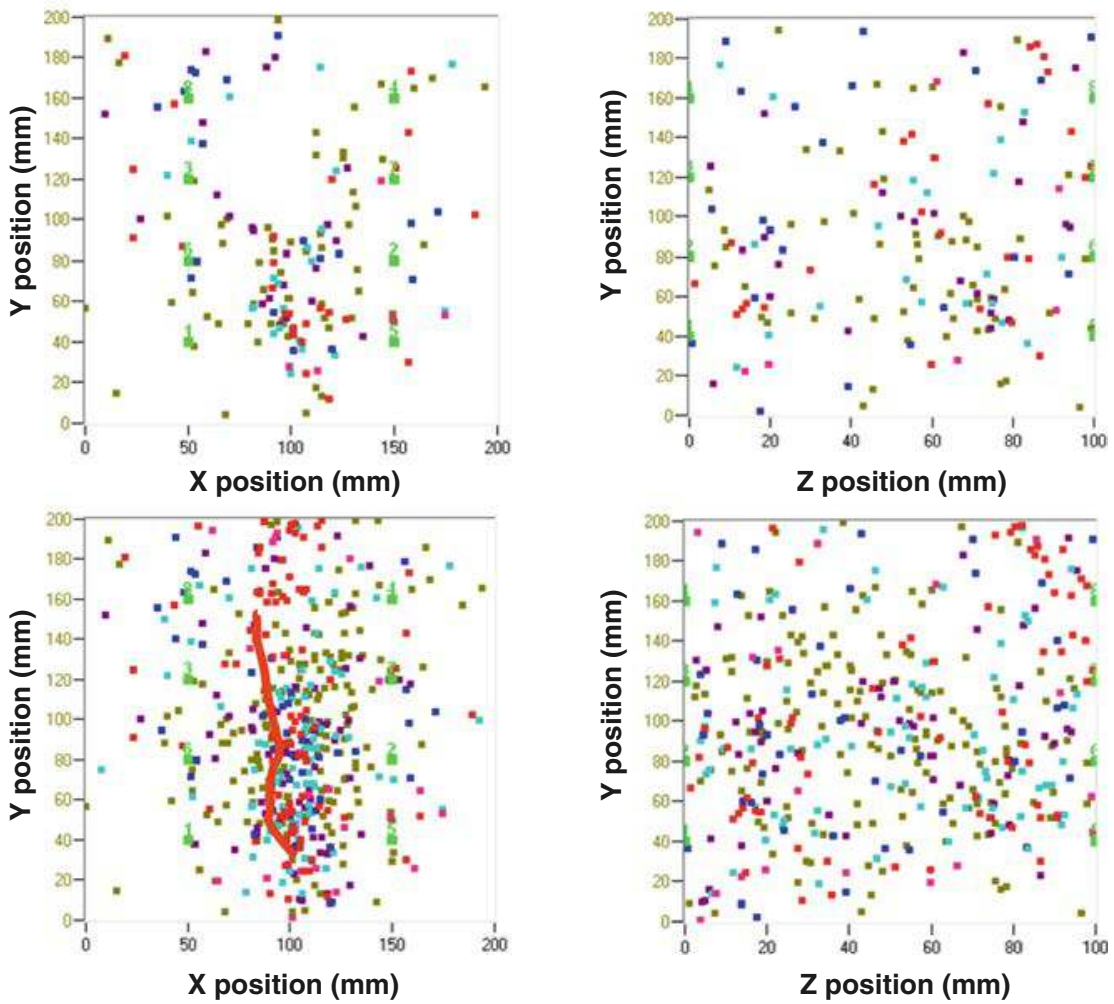

During basic creep, events are arbitrarily distributed and diffused along the length $(x, y)$ and the depth $(y, z)$ of the specimen (Fig. 5a). During desiccation, the number of $\mathrm{AE}$ events increases with a higher rate and more energetic events, especially at the surfaces subjected to drying (Fig. 5b). Those events are highly 
dependent on desiccation. In fact, the non uniform desiccation (humidity gradient) induces a non uniform shrinkage in the specimen and thus presents structural consequences [26, 27]. Then, events begin to localize at the front of the notch in the zone of the maximum tensile stress. As the average stress along the ligament surface is lower than the stress in front of the crack, microcracks relax the stress in front of the FPZ by the creation of new surfaces. Then, events follow a conical progress before the total failure where there is an emission of high amplitude and energetic signals (Fig. 5c). Those results allow us to understand the influence of creep on the brittleness of concrete observed during the failure of beams subjected to creep [7, 28]. Note here that the relative kinetics of acoustic waves does not present an important variation during the test.

\subsection{Correlation between creep displacement and AE parameters}

The correlation between creep displacement and the characteristics of AE signals collected during creep is shown in Fig. 6. The AE activity is important during primary creep with the emission of high amplitude signals and then decreases and stabilizes during secondary creep. At the moment where the beam was subjected to desiccation, the number of AE hits increases quickly with the emission of high amplitude signals, then decreases progressively in correlation with shrinkage. The cumulated AE energy follows the same evolution and gives informations on the crack initiation that progress until the failure. Thus, it could be related to the fracture energy measured on a global scale. This finding strengthens the presumption that the acoustic events recorded during creep are related to the creation of micro-cracks or in other terms the damage occurring inside the material under creep.

\subsection{Multivariable data clustering of AE signals}

The quantitative understanding of the physical processes and the microstructural phenomena that control the fracture behaviour on the macroscopic scale is poor. During the last years, quantitative evaluation of fracture processes in concrete consisted in evaluating the different mode of failure and stress fields based on moment tensors [29-31] and some AE indices as the average frequency and the RA value which is defined by the rise time to the peak amplitude ratio [32]. It appears then necessary to take the analysis further to obtain information about the physical mechanisms, origin of the AE signatures. For this, a multi variable analysis of the recorded acoustic signals is proposed to discriminate the damage mechanisms in the material according to the typical AE signals and their apparition chronology.

For the classification process of the monitored $\mathrm{AE}$ data under creep, the non supervised method $K$-means associated with a principal component analysis (PCA) and the dendrogram are proposed [33]. The $K$-means method allows obtaining a non-supervised classification in $\mathrm{n}$ class representative of the $\mathrm{n}$ damage mechanisms in the case of multidimensional data
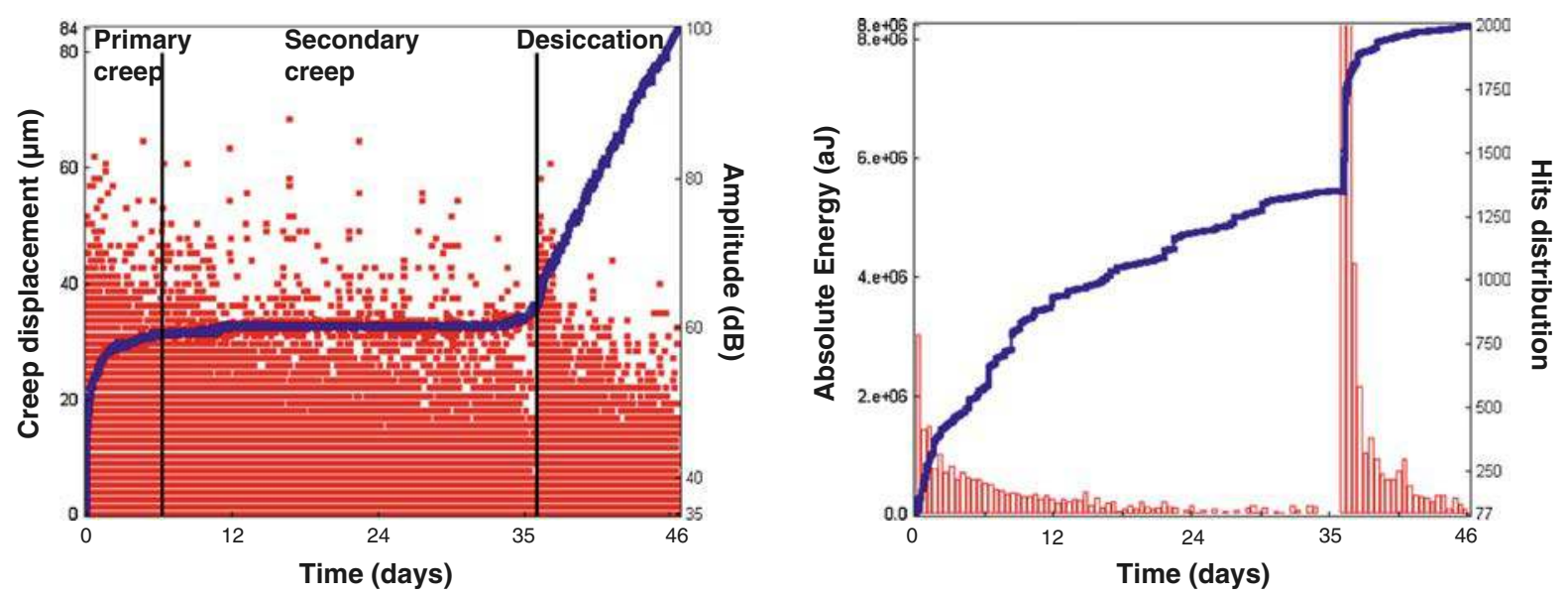

Fig. 6 Correlation between creep displacement and AE hits amplitude (left); correlation between the cumulated AE energy and the distribution of the AE hits during creep test (right) 


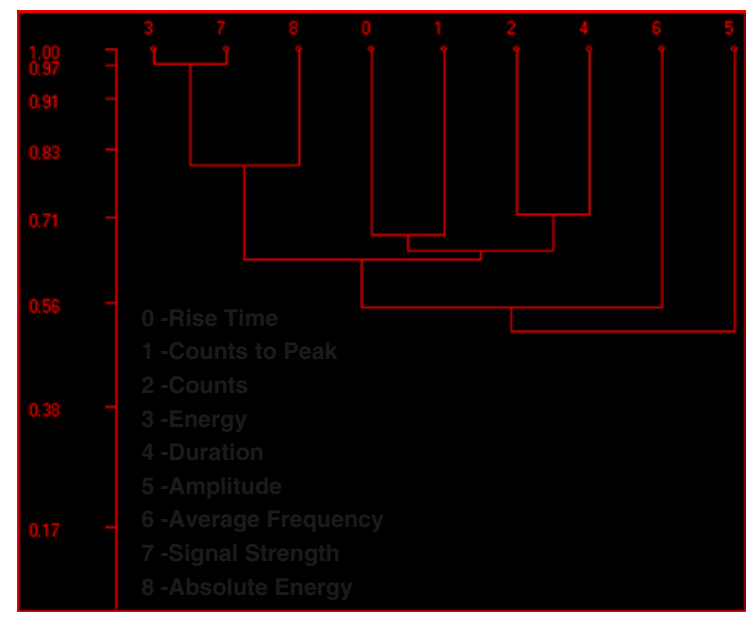

Fig. 7 Correlation dendrogram of AE features

[34]. The PCA method is achieved in order to improve the visualisation of the classification result by reducing the dimension of the data [35]. In the nonsupervised method each signal can be associated to a pattern composed of multiple relevant features extracted from the random AE waveforms (amplitude, energy, rising time, average frequency...). Those parameters can be correlated and consequently redundant. It is then necessary to choose those descriptors wisely. The parameters were classified hierarchically with the dendrogram (Fig. 7) which exhibits the correlation level among the AE features. The correlation level was set to 0.9 and the descriptors were normalized in the interval of $[-1 ; 1]$ to impose an

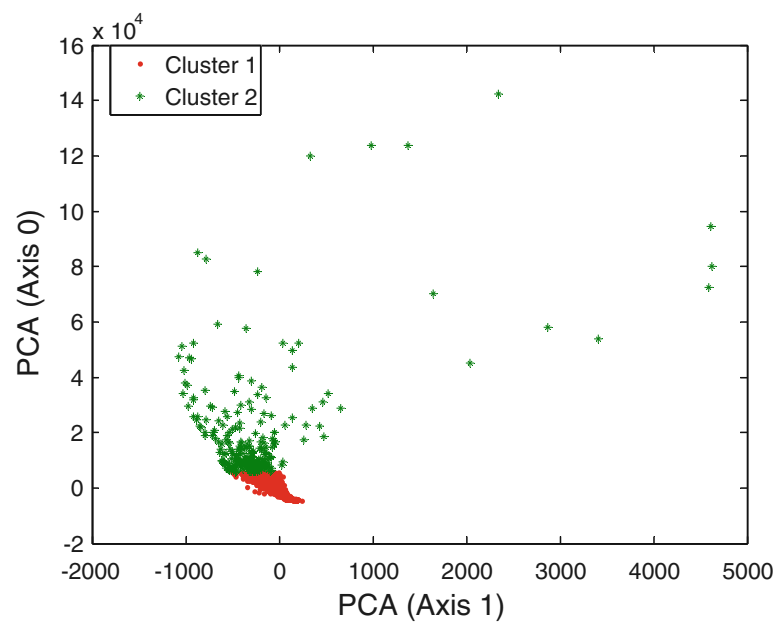

equivalent weight factor to each $\mathrm{AE}$ component. The descriptors used are the energy, the absolute energy, the amplitude, the rise time, the counts, the counts to peak, the average frequency and the duration of the signals.

The results of the $K$-means method are presented in Fig. 8 in 2D in function of the first and second principal components that represent the most important variance of AE parameters. Two clusters are distinguished for basic creep and three for desiccation creep. The clusters are well separated and discriminated.

In the case of basic creep, the first cluster corresponds to signals of weak energy while the second cluster corresponds to signals of higher energy (Fig. 9). For desiccation creep, the same behaviour is observed for the clusters 1 and 2 and the additional cluster 3 is characterized by signals of very weak energy. The apparition chronology of these clusters shows that the first is the most distinguished damage mechanism during basic creep and involves much more numerous AE hits than the second class (Fig. 10). During desiccation creep, the same trend is observed for the first two clusters and the AE hits distribution of the third cluster appears the most important mainly at the beginning of desiccation and decreases with time. In addition, the number of AE hits for the clusters 1 and 2 increases in desiccation in comparison with basic creep.

The number of hits by amplitude recorded was averaged to create an experimental distribution of the AE hits amplitude for each cluster and was fitted with a

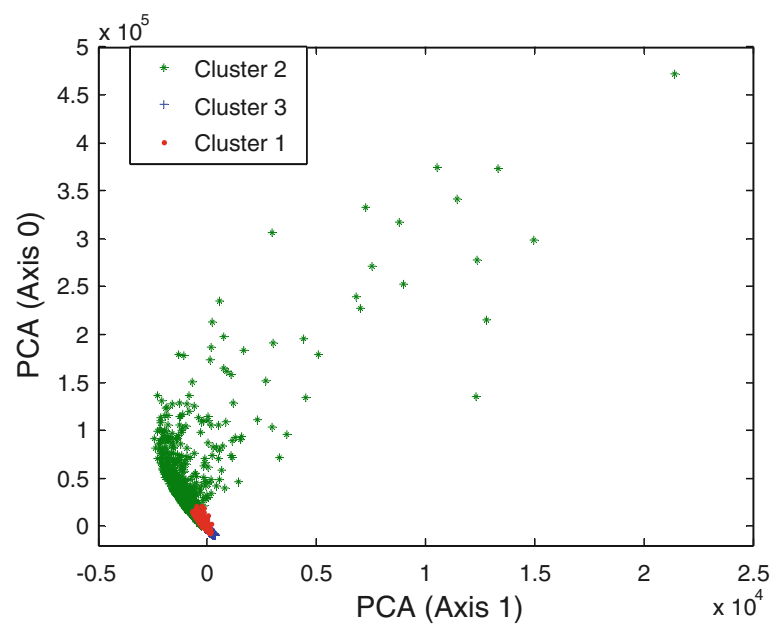

Fig. 8 Visualization of the PAC clusters for basic (left) and desiccation creep (right) 

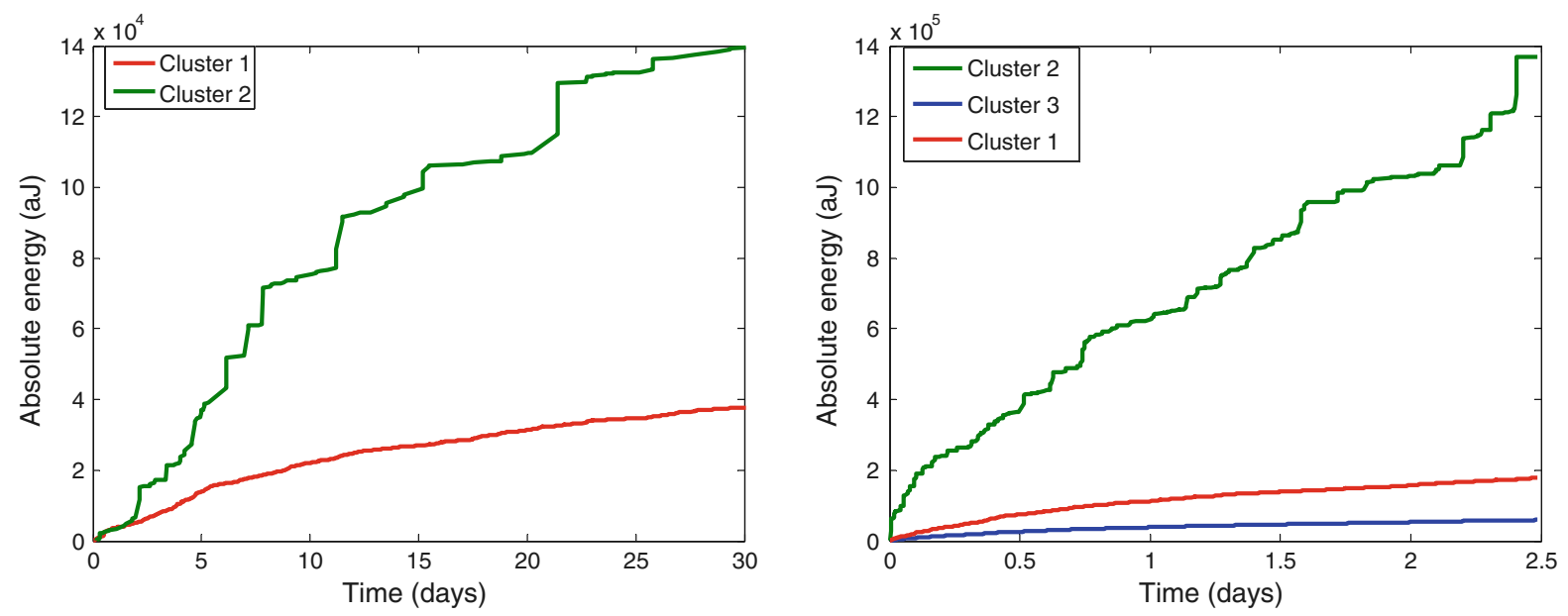

Fig. 9 Cumulated energy for each cluster during basic (left) and desiccation creep (right)
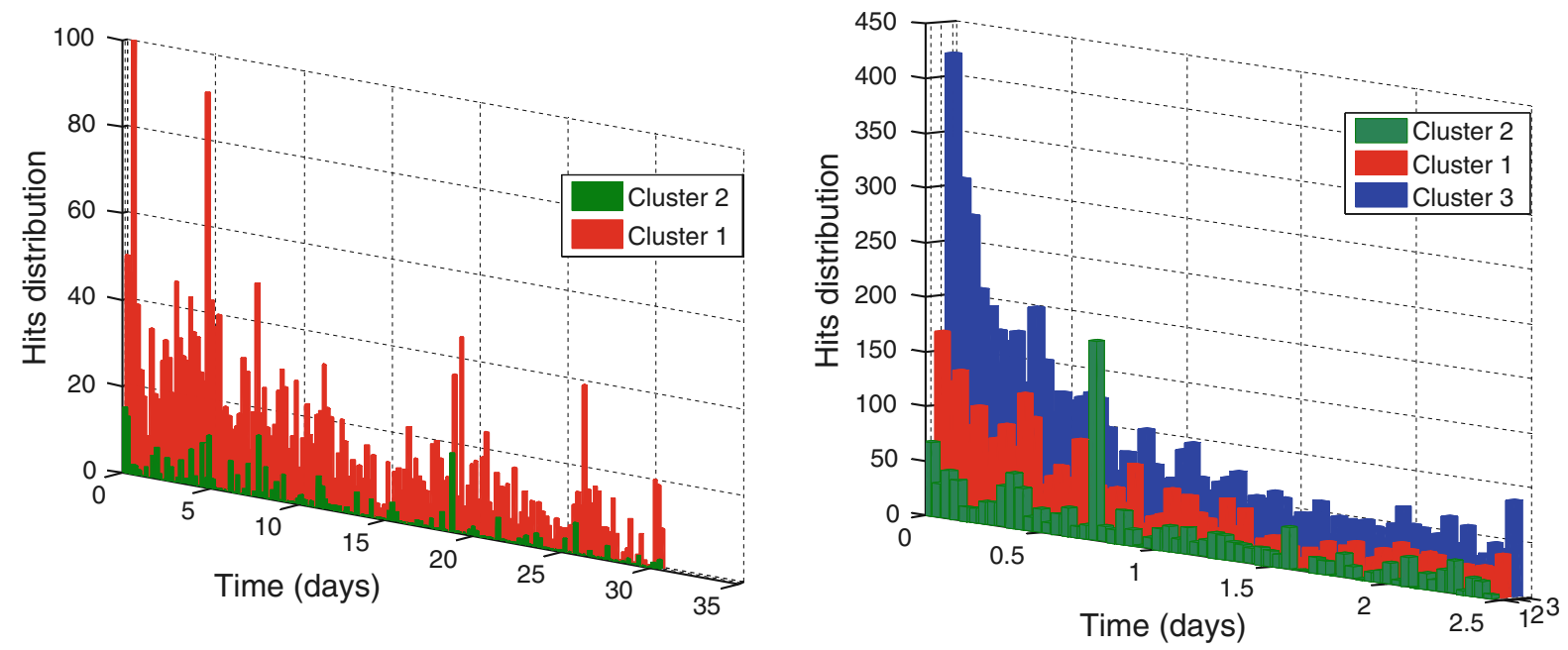

Fig. 10 Apparition Chronology of the clusters during basic (left) and desiccation creep (right)

statistical Laplace-Gauss model. The Laplace-Gauss model was characterized by two parameters: the mode, which is the population mean and the range which represents the full width at half maximum.

$f_{(x)}=\frac{1}{\sigma \sqrt{2 \pi}} \mathrm{e}^{-\frac{1}{2}\left(\frac{x-m}{\sigma}\right)^{2}}$

where $f_{(x)}$ is the statistical variation of the population, $\sigma$ the population standard deviation, $x$ the studied parameter and $m$ the population mean.

Figure 11 shows the experimental distribution and the corresponding statistical law of the $\mathrm{AE}$ hits amplitude for each class. The mode of the AE hits amplitude distribution for the first cluster is $42 \mathrm{~dB}$ and the range is between 36 and $47 \mathrm{~dB}$ and can be associated to microcracking at the matrix-aggregate interface [36]. For the second class, the mode is $50 \mathrm{~dB}$ and the range is between 42 and $59 \mathrm{~dB}$ and can be associated to micro-cracking in the matrix [36]. For the third cluster, the mode is $37 \mathrm{~dB}$ and the range is between 35 and $41 \mathrm{~dB}$. Based on the variation of the AE parameters, this cluster could correspond to signals due to drying as liquid transfer in concrete [37, 38] and cavitation [39]. Note that the differences between ranges of amplitude of classes obtained here could be different for others specimen geometries and recording system parameters. The ranges have to be considered as relative differences. 

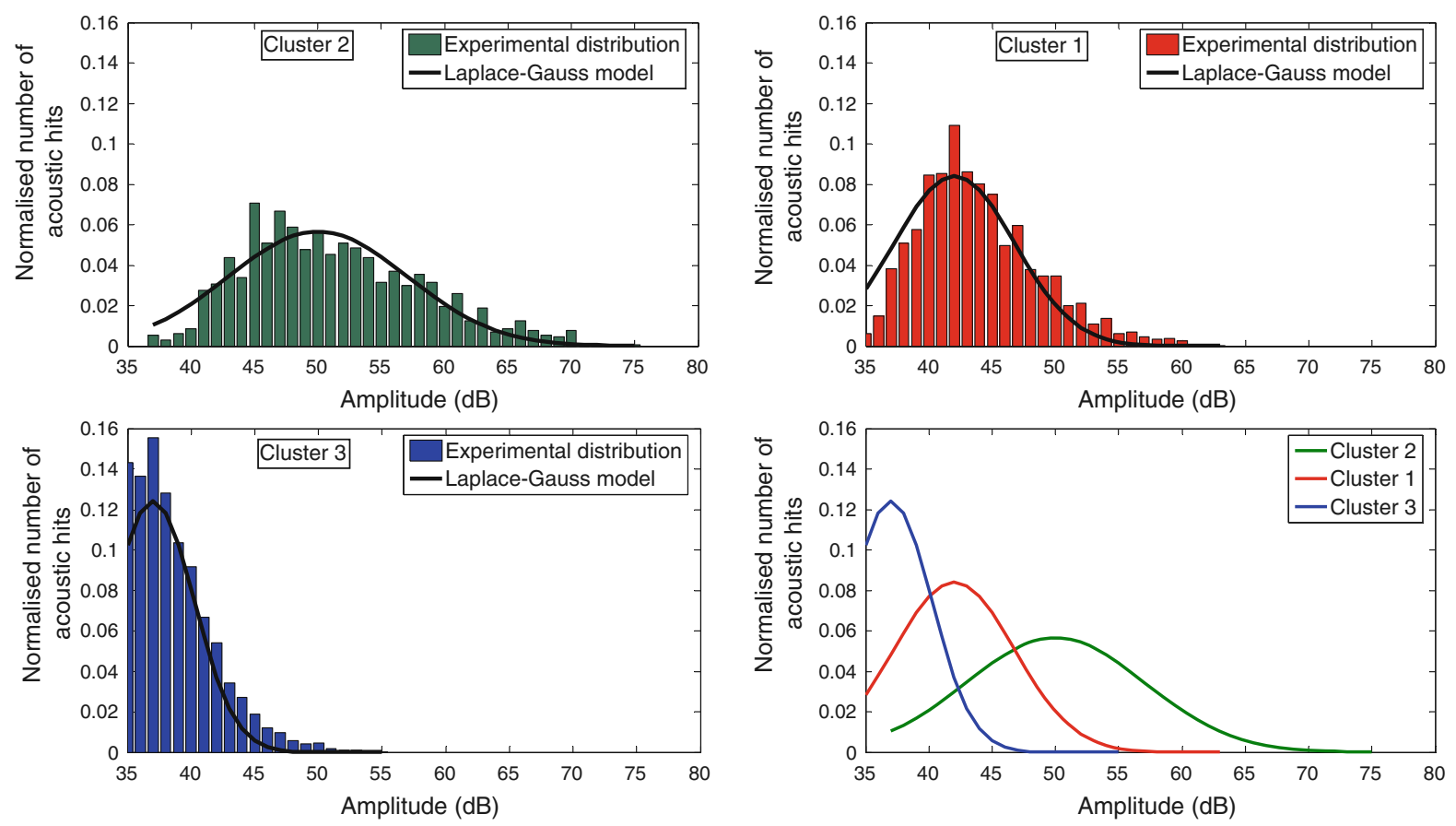

Fig. 11 Experimental and statistical AE hits amplitude distributions for each cluster
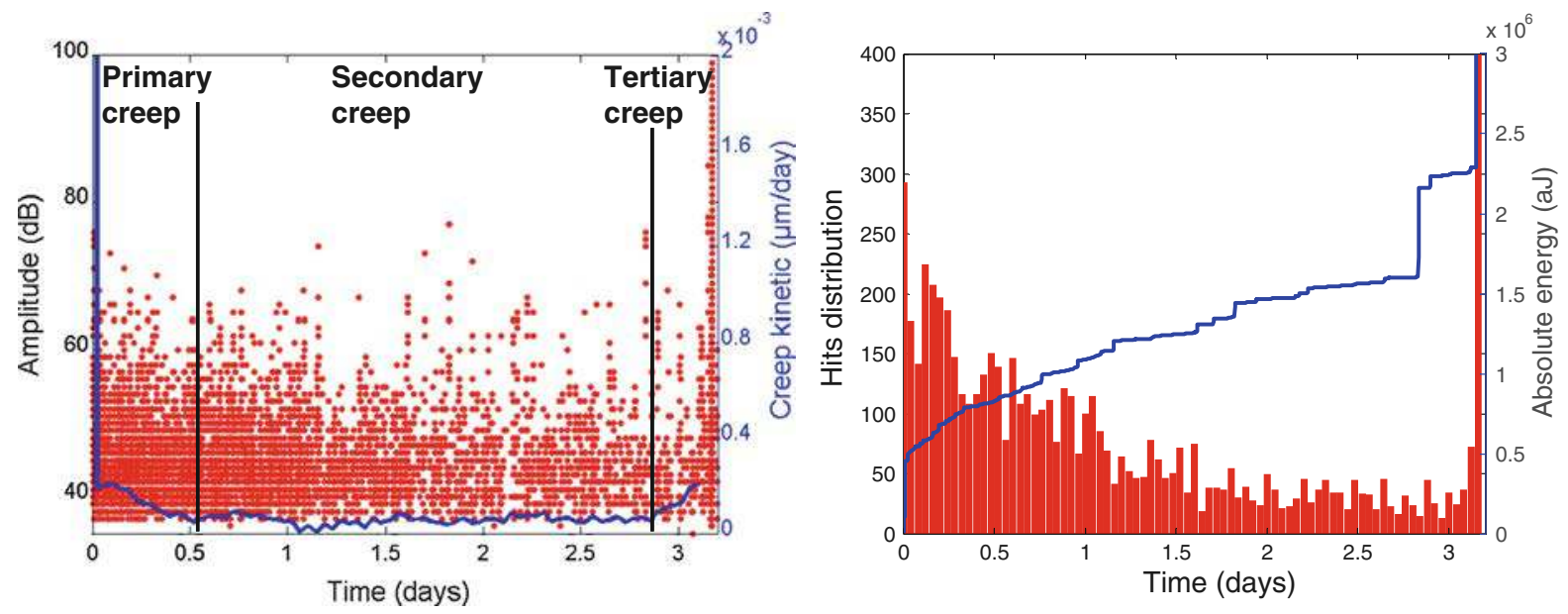

Fig. 12 Correlation between the creep kinetic and the AE hits amplitude (left); correlation between the cumulated AE energy and the distribution of the AE hits (right)

Through this approach, we have shown that it is possible, using the AE method, to identify the most critical damage mechanisms leading to the final failure of concrete. In order to study the damage evolution during the three creep phases at the micro-structural level and more particularly tertiary creep, the $\mathrm{AE}$ technique was also used during desiccation creep tests. The possibility of assessing time to failure of the tested beams from AE is also investigated.

\section{Monitoring of concrete beams during desiccation creep tests}

Figure 12 presents the evolution of the AE activity during the desiccation creep test at $70 \%$. At the moment of load application, the AE activity is important with AE signals of high amplitude corresponding to microcracks in the beam and to noises at the contact between the beam and the jack. This part 
was removed and the AE activity was followed during the three distinct phases of creep corresponding to the evolution of creep displacement into three regimes: primary creep, which corresponds to a fast decrease of strain kinetic under the initial load, followed by secondary creep, which corresponds to a quasiconstant strain kinetic, and tertiary creep in which the strain kinetic increases quickly leading to the global failure of the beams. Those phases generate different signals covering different ranges of amplitude and corresponding to different damage mechanisms.

The AE activity is important during primary creep with $\mathrm{AE}$ hits of high amplitude and an important emission of AE energy (Fig. 12). The rate decreases in correlation with the rate of creep displacement. During this phase, the events are arbitrary distributed especially in the tension zone (Fig. 13a) and may correspond to the initiation and the development of microcracks inside the material as other physical mechanisms responsible of creep as water and stress redistribution in the beams and consequently microcracking.

During secondary creep, the rate of the AE activity is quasi-constant with a stable evolution of $\mathrm{AE}$ energy (Fig. 12). The number of events continues to increase with different energetic value near the notch (Fig. 13b). This phase corresponds to the apparition of a new damage mechanism due to the extension and the propagation of microcracking. Stresses are also generated by the deformation incompatibility between the aggregate and the cement paste [40, 41]. This could be seen on the localization map which presents events of different energy and which corresponds to different damage mechanisms as micro-cracks at the interface between the matrix and aggregate and in the matrix [42].

During the last phase, creep evolves toward the tertiary creep regime where the strain rate accelerates up to failure. The AE activity increases quickly with the emission of very energetic signals. This phase corresponds to the coalescence and the fast propagation of microcracks generating a localized crack and
Fig. 13 Localisation of AE events during the a primary, b secondary and c tertiary desiccation creep test loaded at $70 \%$
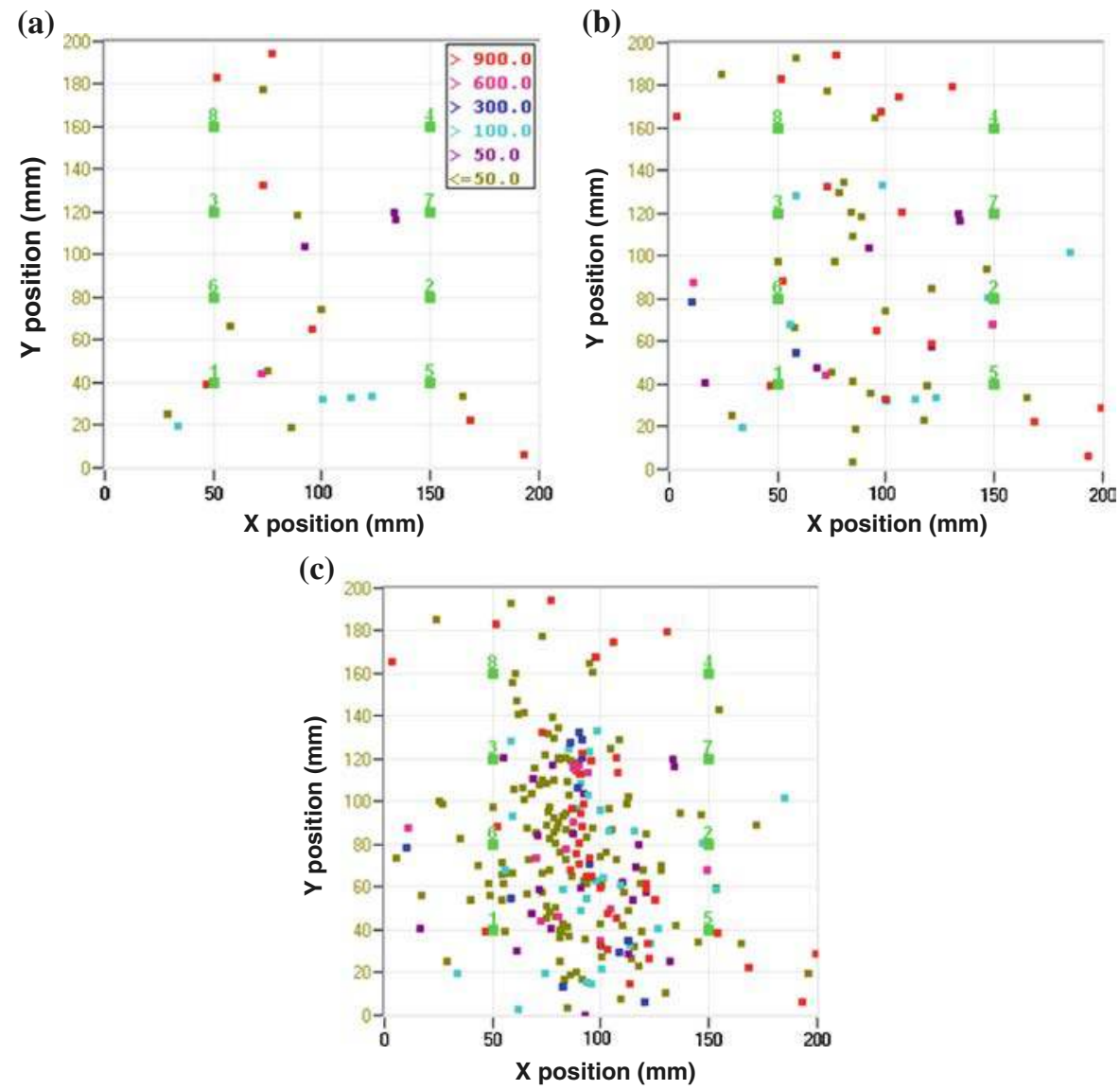


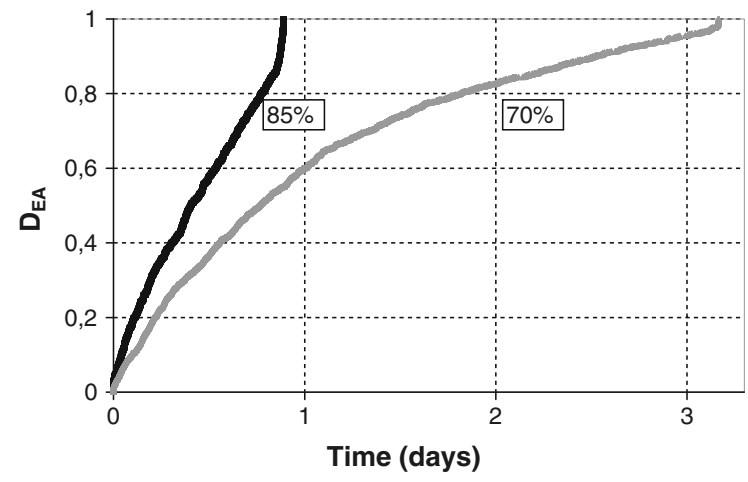

Fig. 14 Evolution of the damage coefficient during desiccation creep

leading to the failure of the specimen in the third day. The amplitude of the AE signals in this phase covers different ranges and reaches sometimes $100 \mathrm{~dB}$ at the failure where the events begin to concentrate in the cracking zone to create finally a macroscopic crack (Fig. 13c).

The stress concentration and redistribution are responsible of the failure and depend highly on the rate of loading and the loading condition. The rate of stress modifies the crack development and causes a slow and stable increase of microcracks until the unstable condition is reached during tertiary creep. This structural damage can be correlated to the evolution of microcracks or hits by relating the rate of the cumulated number of $\mathrm{AE}$ hits $(N)$ and the number obtained at the end of the test $\left(N_{\max }\right)$, corresponding to the total failure where the scalar damage value is equal to 1 [43]:

$D_{\mathrm{EA}}=\frac{N}{N_{\max }}$

where $N_{\max }=3,425$ and $N_{\max }=5,900$ for the beams loaded at 85 and $70 \%$ respectively. Figure 14 shows the evolution of the damage coefficient during flexural creep tests at 70 and $85 \%$. The rate of damage measured for the creep at $85 \%$ is more important in correlation with the rate of loading and the kinetics of creep displacement.

Before the failure, creep displacement increases with an exponential function and residual life-time duration can be then estimated. This damage accumulation evolves as a bathtub-shaped curve and can be described using a Weibull function [44]. That suggests a method to predict the failure by following the $\mathrm{AE}$ activity during creep and allows estimating the degree of concrete deterioration at an early stage of the deformation before the macrocrack formation. But it needs more creep tests with different specimen sizes and loading conditions.

\section{Conclusion}

An experimental investigation concerning the use of the $\mathrm{AE}$ method to characterize local damage and to analyze the physical mechanisms underlying creep of concrete has been carried out. A good correlation was observed between creep displacement and the variation of the AE parameters. The coupling between creep and damage seems to be more important in desiccation. As a part of the investigation, quantitative analysis of the AE data was applied and characteristics of individual microcracks were evaluated and associated to two clusters for basic creep and three clusters for desiccation creep. The differences of the $\mathrm{AE}$ activity during the three regimes of creep displacement were identified. The state of damage increases with the rate of loading and based on this study we could have sufficient data in order to predict the non linear creep and the failure of concrete. In order to have more information on the microstructural effect and the heterogeneity of concrete, similar creep tests will be also realized on mortar beams and monitored with the AE technique. Those tests will provide additional information on the time dependency of each identified damage mechanism and the effect of aggregate on the fracture behaviour. The possibility of combining the multivariable data clustering with the moment tensor will be also studied.

Acknowledgments This study has been performed in the project MEFISTO which is supported by the French National Research Agency (ANR-Agence Nationale pour la Recherche) in the program "Villes Durables" (Sustainable Cities) under Grant Number VD08_323065.

\section{References}

1. Mazzotti C, Savoia M (2002) Nonlinear creep, Poisson's ration, and creep-damage interaction of concrete in compression. ACI Mater J 99:450-457

2. Masuero JR, Creus GJ (1995) Crack growth initiation in concrete like materials in the presence of creep. Nucl Eng Des 156:209-218 
3. Bazant ZP, Li Y (1997) Cohesive crack with rate-dependent opening and viscoelasticity: I. mathematical model and scaling. Int J Fract 86:247-265

4. Bissonnette B, Pigeon M (2000) Le comportement viscoélastique du béton en traction et la compatibilité déformationnelle des réparations. Mater Struct 33:108-118

5. Altoubat SA, Lange DA (2001) Creep, shrinkage, and cracking of restrained concrete at early age. ACI Mater J 98(4):323-331

6. Rossi P, Godart N, Robert JL, Gervais JP, Bruhat D (1994) Investigation of the basic creep of concrete by acoustic emission. Mater Struct 27:510-514

7. Saliba J, Loukili A, Grondin F, Regoin J-P (2012) Study of creep-damage coupling in concrete by acoustic emission technique. Mater Struct 45(9):1389-1401

8. Omar M, Loukili A, Pijaudier-Cabot G, Le Pape Y (2009) Creep-damage coupled effects: experimental investigation on bending beams with various sizes. J Mater Civ Eng 21:65-72

9. Cook DJ, Haque MN (1974) The tensile creep and fracture of desiccated concrete and mortar on water sorption. Matér Constr 7(39):191-196

10. Shah SP, Chandra S (1970) Fracture of concrete subjected to cyclic and sustained loading. ACI Mater J 67(10):816-825

11. Liniers AD (1987) Microcracking of concrete under compression and its influence on tensile strength. Mater Struct 20:111-116

12. Carpinteri A, Valente S, Zhou FP, Ferrara G, Melchiorri G (1997) Tensile and flexural creep rupture tests on partiallydamaged concrete specimens. Mater Struct 30:269-276

13. Denarié E, Cécot C, Huet C (2006) Characterization of creep and crack growth interactions in the fracture behaviour of concrete. Cem Concr Res 36:571-575

14. Granger S, Loukili A, Pijaudier-Cabot G, Chanvillard G (2007) Experimental characterization of the self-healing of cracks in an ultra high performance cementitious material: mechanical tests and acoustic emission analysis. Cem Concr Res 37:519-527

15. Otsuka K, Date H (2000) Fracture process zone in concrete tension specimen. Eng Fract Mech 65:111-131

16. Chen B, Liu J (2004) Effect of aggregate on the fracture behavior of high strength concrete. Constr Build Mater 18:585-590

17. Wu K, Chen B, Yao W (2000) Study on the AE characteristics of fracture process of mortar, concrete and steel-fiberreinforced concrete beams. Cem Concr Res 30:1495-1500

18. Landis EN, Shah SP (1995) The influence of microcracking on the mechanical behaviour of cement based materials. Cem Based Mater 2:105-118

19. RILEM 50-FMC Recommendation (1985) Determination of fracture energy of mortar and concrete by means of threepoint bend test on notched beams. Mater Struct 18:285-290

20. RILEM TC212-ACD Recommendation (2010) Acoustic emission and related NDE techniques for crack detection and damage evaluation in concrete. Mater Struct 43:1177-1181

21. Bazant ZP, Chern JC (1985) Concrete creep at variable humidity: constitutive law and mechanism. Matér Constr 18(103): $1-20$

22. Bazant ZP, Yunping X (1994) Drying creep of concrete: constitutive model and new experiments separating its mechanisms. Mater Struct 27:3-14
23. Ngab AS, Slate FO, Nilson AH (1981) Microcracking and time-dependent strains in high strength concrete. ACI Mater J 11:262-268

24. Meyers BL, Slate FO (1969) Relationship between timedependent deformation and micro-cracking of plain concrete. ACI Mater J 66(1):60-68

25. Bazant ZP, Gettu R (1992) Rate effects and load relaxation in static fracture of concrete. ACI Mater J 89(5):456 $-468$

26. Bazant ZP, Raftshol WJ (1982) Effect of cracking in drying and shrinkage specimens. Cem Concr Res 12:209-226

27. Bisschop J, van Mier JGM (2002) How to study drying shrinkage microcracking in cement-based materials using optical and scanning electron microscopy? Cem Concr Res 32:279-287

28. Saliba J, Grondin F, Loukili A, Regoin J-P (2010) Coupling creep and damage in concrete under high sustained loading. In: Proceedings of the 7 th international conference on fracture mechanics of concrete and concrete structures, Framcos-7

29. Ohtsu M, Kaminaga Y, Munwam MC (1999) Experimental and numerical crack analysis of mixed-mode failure in concrete by acoustic emission and boundary element method. Constr Build Mater 13:57-64

30. Fink F, Yamanouchi M, Reinhardt H, Grosse C (2003) Evaluation of mode I failure of concrete in a splitting test using acoustic emission technique. Int J Fract 124:139-152

31. Grosse CU, Fink F (2006) Quantitative evaluation of fracture processes in concrete using signal based acoustic emission techniques. Cem Concr Compos 28:330-336

32. Aggelis DG (2011) Classification of cracking mode in concrete by acoustic emission parameters. Mech Res Commun 38:153-157

33. Kostopoulos V, Loutas TH, Kontsos A, Sotiriadis G, Pappas YZ (2003) On the identification of the failure mechanisms in oxide/oxide composites using acoustic emission. NDT\&E Int 36:571-580

34. Likas A, Vlassis N, Verbeek JJ (2003) The global K-means clustering algorithm. Pattern Recognit 36:451-461

35. Oja E (1989) Neural networks, principal components, and subspaces. Int J Neural Syst 1:61-68

36. Rossi P, Robert JL, Gervais JP, Bruhat D (1989) Identification of the physical mechanisms underlying acoustic emissions during the cracking of concrete. Mater Struct 22:194-198

37. Chotard T, Quet A, Ersen A, Smith A (2006) Application of the acoustic emission technique to characterise liquid transfer in a porous ceramic during drying. J Eur Ceram Soc 26:1075-1084

38. Chotard T, Smith A, Quet A (2007) Characterisation of liquid transfer processes and water adsorption mechanism on a porous ceramic by acoustic emission means. J Eur Ceram Soc 27:457-462

39. Lura P, Couch J, Jensen OM, Weiss J (2009) Early-age acoustic emission measurements in hydrating cement paste: evidence for cavitation during solidification due to selfdesiccation. Cem Concr Res 39:861-867

40. Saliba J, Grondin F, Matallah M, Loukili A, Boussa H (2013) Relevance of a mesoscopic modelling for the coupling between creep and damage in concrete. Mech TimeDepend Mater. doi:10.1007/s11043-012-9199-4 
41. Idiart AE, Lopez CM, Carol I (2011) Modeling of drying shrinkage of concrete specimens at the meso-level. Mater Struct 44:415-435

42. Saliba J (2012) Contribution of the acoustic emission technique in the understanding and the modelling of the coupling between creep and damage in concrete. PHD thesis, Ecole Centrale de Nantes (in French)
43. Carpinteri A, Lacidogna G, Pugno N (2007) Structural damage diagnosis and life-time assessment by acoustic emission monitoring. Eng Fract Mech 74:273-289

44. Verstrynge E, Schueremans L, Gemert DV, Wevers M (2009) Monitoring and predicting masonry's creep failure with the acoustic emission technique. NDT\&E Int 42:518-523 